\title{
Study on Scientific Research Management of Universities for Traditional Chinese Medicine
}

\author{
Yuan Sun ${ }^{1, a}$ and Chun-Yan $\mathrm{Li}^{2, \mathrm{~b}}$ \\ ${ }^{1}$ Science and Technology Department, Hubei University of traditional Chinese Medicine, Wuhan, \\ China \\ ${ }^{2}$ School Of Marxism, Hubei University of traditional Chinese Medicine, Wuhan, China \\ aelyn1202@hbtcm.edu.cn, b156738577@qq.com
}

Keywords: universities for traditional Chinese medicine; scientific research management; science; high efficiency.

\begin{abstract}
The paper analyzes some problems existed in scientific research management of universities for Traditional Chinese Medicine, such as behindhand management conception, behindhand system of administration in scientific research management, disordered funds management for scientific research and so on, puts forward to several suggestions that people in universities for Traditional Chinese Medicine update their conceptions in scientific research management, create new management system in scientific projects, perfect regulations of scientific research funds. These are helpful for researchers to have a better understanding of problems existed in scientific research management, furthermore, to form a more effective scientific research management(SRM) system which can promote scientific creation and development of universities
\end{abstract} for Traditional Chinese Medicine (TCM).

Since the 21st century, Science and technology innovation has become the leading factor of success in the international competition for the countries of the world. Science and technology competitiveness will determine the destiny and prospects $\mathrm{f}$ a country or a region in the future competitive structure and become the key to the maintenance of the nation security and the national development. The priorities in the development strategy of our country are the construction of national innovation system and the promotion for scientific and technological innovation. What is noteworthy is that scientific research in universities in the former is the front of knowledge innovation. Especially, TCM universities which are the bases of scientific research play a decisive and irreplaceable role,

They can adapt to the request of the ages in the condition of their constant innovation. Only if we strengthen the scientific management of TCM universities and promote the ability in research and innovation can TCM cause bring preferably its superiority into full play on the basis of keeping traditional features and stand firm in international community.

Scientific research is an exploratory and creative work, It is an important means of higher education personnel training and the power to promote the development of science and technology. Scientific management is a process of scientific research activities to plan, coordinate, organize and control, etc. It mainly includes the division of scientific research types, the formulation of scientific research, the management of projects and achievements and so on. For the specialized TCM universities, good scientific research is necessary measures for subject construction and development to inherit and carry forward the tradition.

\section{Introduction}

Currently, there are some common problems in many TCM universities as follows. Most of TCM universities prefer to the intuitive quantitative evaluation, rather than qualitative evaluation; the quantities of domestic first-class TCM colleges or universities haven't changed much in recent 
years, the international famous TCM experts can be counted on our fingers. Some researchers have administrative duties in their additional post, which leads to the unbalance distribution of academic resources, some booming subjects and others standstill; In the process of higher scientific research project application or implementation, the universities are lack of effective organizer to act as a leader, which goes against striving to make technological breakthrough; some researchers attach importance to projects application, but neglect final project measurement or the protection of intellectual property resulting in the loss of opportunity of research achievements to turn into social benefits.

\section{Analysis}

The development of scientific research of TCM universities is inseparable from good management of scientific research work. Scientific research management is a real knowledge, the process of its implementation is interrelated with our national planning, when it promotes the advancement of national science and technology, there are some problems at the same time.

(1) Problems in the management of scientific researcher

Firstly, researchers are relatively scattered in not only TCM universities but also other ordinary universities. The Cooperation and communication between departments and labs are limited, the experiment platforms fail to share their resources, both situations affect the researchers' studies restricts in the face of significant research topic or cross discipline subject research. Secondly, the level of research is relatively low. SCI, CPCI,EI are regarded as important indexes of scientific research achievement for the moment[1], SCI especially, but TCM as one of the quintessence of Chinese culture has not been recognized by some developed countries, which leads to few SCI papers on TCM. Although the situation has improved in recent years, there are still large gaps compared with other comprehensive universities and pharmaceutical universities of other nations.

(2) Problems in the management of scientific research funds

With the rapid development of Chinese medicine, the research funds of TCM universities have increased significantly, problems in the management of scientific research funds are also becoming more and more prominent.

Unreasonable budget of funds. Most teachers are not familiar with financial knowledge, it is difficult for them to expend proportionally in the implementation of scientific research projects, as their project budgets can not really reflect the costs[2].

Privatization of funds. Some teachers carry out researches by keeping away from their universities for the purpose of avoiding the management fee, but they use the research resources of universities in the process of their projects.

Serious loss of scientific research funds[3]. Some teachers submit the expenses of their daily lives in research funds, what's more, someone swindle scientific research funds through false invoices and so on.

Fund management supervision awareness of many universities is not strong. Many universities are lack of a complete set of financial audit oversight mechanisms[4], as a result, their fund management is disordered.

(3) Problems in the management of scientific research projects

The numbers of scientific research project and project funds are one of important indexes of measuring universities comprehensive strength. Problems in the management of scientific research projects exist in the process of application, implementation, conclusion of scientific research project. Aimless topic selection, insufficient innovation and low-grade application form 
are the reasons that the successful rate of scientific research project is low. In the process of some project implementation and conclusion, research funds are not in place in time, some administrative staff fail to supervise. All these impede the smooth progress of the projects.

(4) Problems in the management of achievements in scientific research

Achievements in scientific research includes papers, patents, awards and so on. Most universities have many papers but few patents and very low rate of transformation to productivity, especially universities for TCM, Because of its traditional characteristics and the complexity of its system research, the evaluation criteria of scientific research varies, research achievements are unable to be popularized.

(5) Problems in the evaluation of scientific research achievement

The evaluation of scientific research achievement in most universities is short of integrated planning, for instance, different types or levels of scientific research projects are evaluated by the same system, the evaluation indexes are not reasonable. These influence the enthusiasm and creativity of teachers.

\section{Suggestions}

The problems in the management of scientific research are mainly due to outdated management concepts, inadequate scientific research cognition and management system, weak scientific research team and so on. Only by doing SRM well, can we accelerate the pace of scientific and technological innovation.

(1) Updating the concept of scientific research management and improving the SRM system are effective methods to perfect the management level of university's science research management, to promote the effective transformation of scientific research achievements and bring some economical profits and social profits. Based on policy advocacy and professional training, SRM team tends to be more specialized and well-qualified. In the meantime, they should strengthen the concept of intellectual property protection and effectively manage and restrain the loss of patent intellectual property. they can establish the market conception to close scientific research and production together in order to promote scientific research result effective transformation.

(2) Innovating scientific research evaluation system is the main method to stimulate the enthusiasm of researchers. Universities for TCM can establish feasible scientific research achievements reward mechanism according to their types. In the second place, it is necessary that the reward mechanism is oriented to high-level achievements and talents and is one of the standard for researchers' annual assessment and academic title evaluation.

(3) Improving the scientific research fund management system of universities for TCM can bring the maximum efficiency for scientific research projects. According to the real situation of universities for TCM, managers can formulate detailed operational fund management system and stipulate specifically budgets, expense, outdialings and so on. They can pinpoint responsibility subject in a hierarchical manner in order to monitor and control unreasonable expenses. In addition, setting up scientific research information management system favors the managers to form a dynamic supervision system and obtain accurate management information.

\section{Conclusions}

To sum up, the SRM of universities for TCM should pay attention to process management. 
Only if they constantly updated their management concept, innovate SRM patterns and promote the industrialization of scientific and technological achievements can they develop their talent and discipline advantage and further enhance the overall strength. Also only like this, scientific research in TCM will be better and better.

\section{Acknowledgement}

This paper is sponsored by scientific research project of Education Department of Hubei (NO.Q 20172010)

\section{References}

[1] Yanjuan Qin, On the Problems of the Administration of the Scientific Researches of Higher Education Institutions and Countermeasures[D]. Changsha: Hunan Normal University, 2006. 5-19.

[2] Huizhi Zhao, Some thoughts on strengthening the management of research funds in universities[J]. Modern Economic Information, 2010 (23) 112-114.

[3] Shuangqing Liu, Xiaosong Wu, Kuiwu Wang, The Quartet of improving SRM in universities[J]. Science and technology of Chinese universities, 2013 (11) 20-21.

[4] Bing Zhu, Thoughts on strengthening the management of research funds in universities[J/OL]. People's Tribune, http://paper.people.com.cn/rmlt/html. 